\title{
Influence of NH4-Rb substitution on the phase transitions with different kinds of proton disorder in mixed [( $\mathrm{NH} 4) 1$ - $\mathrm{xRbx}] 3 \mathrm{H}(\mathrm{SO} 4) 2$ crystals
}

\section{Authors: A.I. Baranov, V.V. Dolbinina, E.D.} Yakushkin, V.Yu. Vinnichenko, V. Hugo Schmidt, and S. Lanceros-Mendez

This is an Accepted Manuscript of an article published in Ferroelectrics on [date of publication], available online: http://www.tandfonline.com/10.1080/00150199808015049.

A.I. Baranov, V.V. Dolbinina, E.D. Yakushkin, V.Yu. Vinnichenko, V.H. Schmidt, and S. Lanceros-Mendez, "Influence of NH4-Rb substitution on the phase transitions with different kinds of proton disorder in mixed [(NH4)1-xRbx]3H(SO4)2 crystals," Ferroelectrics 217, 285-295 (1998). http://dx.doi.org/10.1080/00150199808015049 


\title{
INFLUENCE OF NH $_{4}$-Rb SUBSTITUTION ON THE PHASE TRANSITIONS WITH DIFFERENT KINDS OF PROTON DISORDER IN MIXED $\left[\left(\mathrm{NH}_{4}\right)_{1-x} \mathrm{Rb}_{x}\right]_{3} \mathrm{H}\left(\mathrm{SO}_{4}\right)_{2}$ CRYSTALS
}

\author{
A. I. BARANOV ${ }^{a} *$, V. V. DOLBININA ${ }^{a}$, E. D. YAKUSHKIN ${ }^{a}$, \\ V. YU. VINNICHENKO ${ }^{a}$, V. H. SCHMIDT ${ }^{b}$ \\ and $S$. LANCEROS-MENDEZ ${ }^{b}$ \\ anstitute of Crystallography of RAS, Moscow, 117333, Russia; \\ ${ }^{\mathrm{b}}$ Phys. Dept., Montana State University, Bozeman, MT 59717, USA
}

(Received 24 March 1998; In final form 12 May 1998)

\begin{abstract}
The role of ammonium ions in order-disorder ferroelastic, ferroelectric and structural phase transitions was studied in mixed $\left[\left(\mathrm{NH}_{4}\right)_{1-x} \mathrm{Rb}_{x}\right]_{3} \mathrm{H}\left(\mathrm{SO}_{4}\right)_{2} \quad 0<x<1$ crystals by dielectric spectroscopy and ac calorimetry. A new superprotonic phase was detected in compounds with $x>0.6$. It was found that small $\mathrm{Rb}$ concentrations, $x<0.05$, strongly smear out the temperature anomalies of dielectric constant and specific heat for phase transitions II-III, III-IV, IV-V and V-VIII. At $x>0.09$ these phase transitions are fully suppressed. Finally, for $\mathrm{Rb}$ concentrations $0.05<x<0.9$ a proton glass phase appears below $35 \mathrm{~K}$.
\end{abstract}

Keywords: Glass states; ferroelectrics; ferroelastics; proton disorder

\section{INTRODUCTION}

It is well known that in most ferro/antiferroelectric ammonium containing compounds the $\mathrm{NH}_{4}^{+}$ions strongly influence the ferroelectric and other physical properties. For example, in crystals of the KDP family the substitution of alkali ions by $\mathrm{NH}_{4}^{+}$ions changes the ferroelectric to antiferroelectric ordering. ${ }^{[1]}$ In some compounds like $\mathrm{M}_{2} \mathrm{SO}_{4}$ or $\mathrm{M}(\mathrm{M}=\mathrm{K}$, $\mathrm{Rb}, \mathrm{NH}_{4}, \mathrm{Cs}$ ) the phase diagrams for the alkali metal salts are much simpler

\footnotetext{
*Corresponding author. e-mail: root@theory.incr.msk.su
} 
than for the isomorphous ammonium salts. ${ }^{[2,3]}$ Such differences are displayed most strictly in crystals of the $\mathrm{M}_{3} \mathrm{H}\left(\mathrm{AO}_{4}\right)_{2}$ family where $\mathrm{M}=\mathrm{K}, \mathrm{Rb}, \mathrm{NH}_{4}, \mathrm{Cs}$ and $\mathrm{A}=\mathrm{S}, \mathrm{Se}^{[4-8]}$ In particular, $\left(\mathrm{NH}_{4}\right)_{3} \mathrm{H}\left(\mathrm{SO}_{4}\right)_{2}$ (TAHS) exhibits five successive phase transitions ${ }^{[5,7]}$

$$
\begin{aligned}
& \mathrm{I} \leftarrow 413 \mathrm{~K} \rightarrow \mathrm{II} \rightarrow 265 \mathrm{~K} \rightarrow \mathrm{III} \leftarrow 139 \mathrm{~K} \leftarrow \mathrm{IV} \rightarrow 133 \mathrm{~K} \leftarrow \mathrm{V} \rightarrow 63 \mathrm{~K} \rightarrow \mathrm{VII} \\
& R \overline{3} / m \quad A 2 / a \quad P 2 / n
\end{aligned}
$$

while $\mathrm{Rb}_{3} \mathrm{H}\left(\mathrm{SO}_{4}\right)_{2}$ (TRHS) has symmetry isomorphous to monoclinic phase II of TAHS and undergoes no defined phase transitions from the melting point down to $4 \mathrm{~K} .^{[6,8]}$

At room temperature TAHS is monoclinic with space group $C_{2 h}^{4}(A 2 / a) \cdot{ }^{[9,10]}$ Its crystal structure consists of two structurally inequivalent $\mathrm{NH}_{4}^{+}$ions and $\mathrm{SO}_{4}^{2-}$ groups. $\mathrm{NH}_{4}^{+}(1)$ ions occupy a general position and form pure $\mathrm{NH}_{4}^{+}$layers while $\mathrm{NH}_{4}^{+}$(2) ions occupy a special position on the two-fold axis and form mixed $\mathrm{NH}_{4}^{+}, \mathrm{SO}_{4}^{2-}$ layers. The two adjacent $\mathrm{SO}_{4}^{2-}$ groups are linked by strong symmetrical (at room temperature) hydrogen bonds with length $2.540 \AA$. These acid hydrogen bonds being isolated from each other do not form any network through the crystal. At room temperature the TRHS crystal has the same structure and symmetry space group ${ }^{[1]}$ However the length of acid H-bonds in TRHS $(2.486 \AA)$ is shorter than in TAHS.

The succession of the low temperature phase transitions in TAHS is very sensitive to isotopic $\mathrm{H}-\mathrm{D}$ substitution ${ }^{[8,12]}$ and hydrostatic pressure. ${ }^{[13]}$ Moreover, the first study ${ }^{[14]}$ of mixed $\left[\left(\mathrm{NH}_{4}\right)_{0.14} \mathrm{Rb}_{0.86}\right]_{3} \mathrm{H}\left(\mathrm{SO}_{4}\right)_{2}$ crystals points out that at low temperatures the compounds with $x>0.1$ reveal transitions into a glass phase instead of a ferroelectric phase transition $\mathrm{V}$ VII. These facts suggest that ammonium ions owing to additional rotational degrees of freedom and weak $\mathrm{N}-\mathrm{H} \cdots \mathrm{O}$ hydrogen bonds strongly increase lability of the crystalline lattice of TAHS. Accordingly, mixed $\left[\left(\mathrm{NH}_{4}\right)_{1-x} \mathrm{Rb}_{x}\right]_{3} \mathrm{H}\left(\mathrm{SO}_{4}\right)_{2}$ (TRAHS) crystals are considered as good model substances to clarify the special role of ammonium ions in the peculiar properties of ammonium salts.

In the present work the influence of $\mathrm{NH}_{4}-\mathrm{Rb}$ substitution on the phase transitions and some properties of the mixed crystals $\left[\left(\mathrm{NH}_{4}\right)_{1-x} \mathrm{M}_{\lambda}\right]_{3}$ $\mathrm{H}\left(\mathrm{SO}_{4}\right)_{2}$ have been studied.

\section{EXPERIMENTAL}

Mixed $\left[\left(\mathrm{NH}_{4}\right)_{1-x} \mathrm{Rb}_{x}\right]_{3} \mathrm{H}\left(\mathrm{SO}_{4}\right)_{2}$ single crystals with $x=0,0.03,0.05,0.09$, $0.14,0.18,0.25,0.41,0.50,0.71,0.85$ and 1.0 were grown from water 
solutions by the slow evaporation method. The concentration of the components in solid solutions was determined by direct chemical analysis. The concentrations of $\mathrm{Rb}_{3} \mathrm{H}\left(\mathrm{SO}_{4}\right)_{2}$ in the crystals versus those in the saturated solutions are shown in Figure 1.

An autobalanced Quad Tech 7600 Precision RLC Meter and Tesla BM431-E bridge were used for measurements of the complex dielectric constant in the frequency range $10 \mathrm{~Hz}-200 \mathrm{MHz}$. A closed cycle helium cryostat (Janis Research Co., Inc. Model C210) and home built thermostat were used in the temperature ranges $10-320 \mathrm{~K}$ and $300-600 \mathrm{~K}$, respectively. The samples had the form of rectangular plates with size $0.5 \times 0.5 \times 0.1 \mathrm{~cm}^{3}$ oriented perpendicular to the pseudo-hexagonal axis. Silver paint was used for electrodes. The standard method of admittance plots was used to calculate dc bulk conductivity.

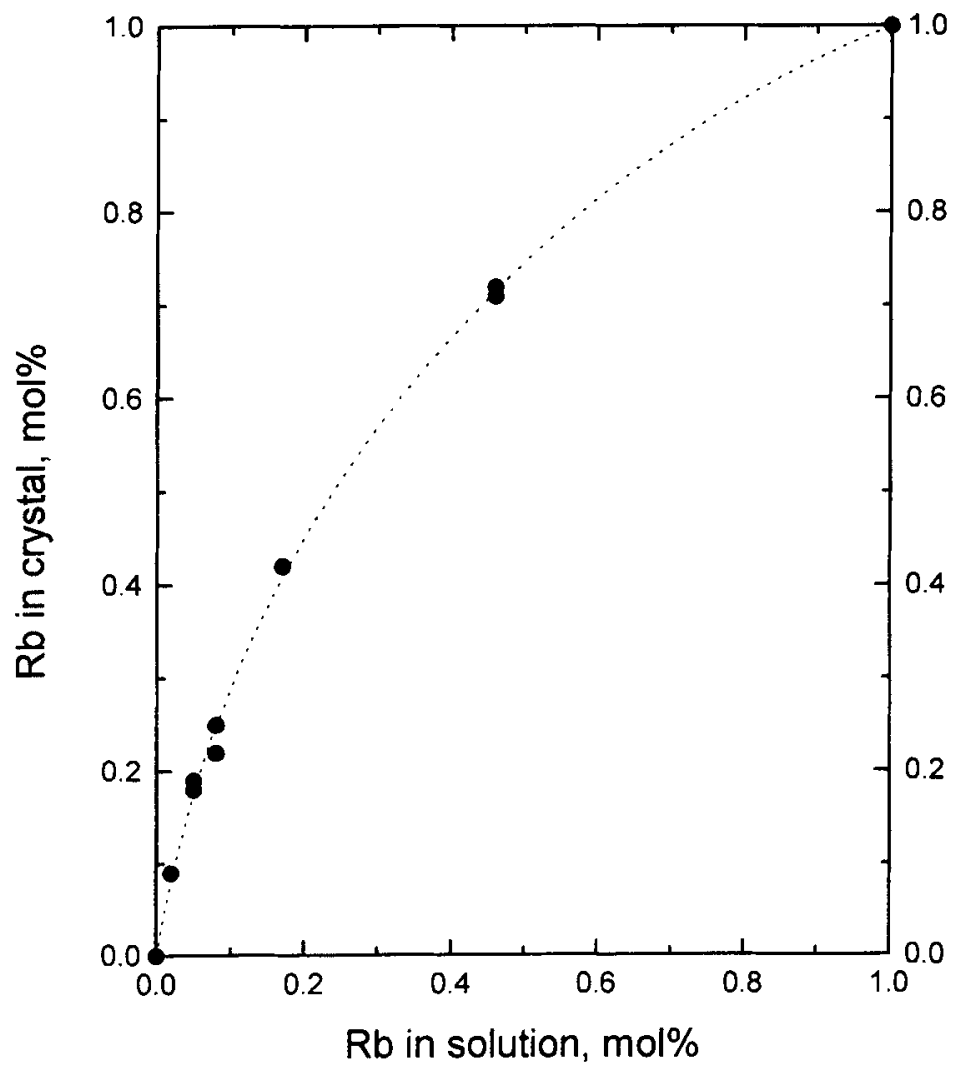

FIGURE $1 \mathrm{Rb}$ content in $\left.\left[\left(\mathrm{NH}_{4}\right)_{1-x} \mathrm{Rb}\right]_{x}\right]_{3} \mathrm{H}\left(\mathrm{SO}_{4}\right)_{2}$ crystals versus $\mathrm{Rb}$ content in saturated water solutions. 
Specific heat measurements were carried out by the ac-calorimetric technique in quasi-static regime with heating/cooling rate of $0.02 \mathrm{deg} / \mathrm{min}$. Thin plates of single crystals with dimensions of $2 \times 2 \times 0.1 \mathrm{~mm}^{3}$ were used as samples.

\section{RESULTS}

\section{1. $\left(\mathrm{NH}_{4}\right)_{3} \mathrm{H}\left(\mathrm{SO}_{4}\right)_{2}$ Crystal}

The results of previous study of anisotropy of dielectric properties of $\left(\mathrm{NH}_{4}\right)_{3} \mathrm{H}\left(\mathrm{AO}_{4}\right)_{2}$ and $\mathrm{Rb}_{3} \mathrm{H}\left(\mathrm{AO}_{4}\right)_{2}{ }^{[5,6,12,14]}$ suggest that below the ferroelastic phase transition I-II these crystals can be considered as electrically biaxial with the predominant direction of the polarization along the pseudotrigonal $c$ axis. Therefore in the present study the measurements of dielectric properties and conductivity of $\left[\left(\mathrm{NH}_{4}\right)_{1-x} \mathrm{Rb}\right]_{3} \mathrm{H}\left(\mathrm{SO}_{4}\right)_{2}$ were carried out on plates oriented perpendicular to the $c$-axis.

Pure TAHS shows well-defined anomalies of dielectric constant and specific heat corresponding to five successive phase transitions (Figs. 1 and 2). Recently it was shown ${ }^{[15]}$ that the high-temperature phase transition $\mathbf{I}-$ II is improper ferroelastic and superprotonic simultaneously. Increasing symmetry from monoclinic $(A 2 / a)$ to trigonal $(R \overline{3} / m)$ is accompanied by dynamical disordering of the acid hydrogen bond network which leads to a high protonic conductivity in Phase I (Fig. 3). The I-II phase transition entropy $\Delta S=2.5 \pm 0.2 \mathrm{cal} \cdot \mathrm{mol}^{-1} \cdot \mathrm{deg}^{-1[16]}$ is close to the configurational entropy $\Delta S=R \ln 3=2.19 \mathrm{cal} \cdot \mathrm{mol}^{-1} \cdot \mathrm{deg}^{-1}$ for this kind of order-disorder phase transition. ${ }^{[17]}$ The quasi-two-dimensional character of conductivity $\sigma_{a} \cong \sigma_{b} \gg \sigma_{c}$ agrees well with the two-dimensional geometry of the disordered acid hydrogen bond network. ${ }^{[17]}$

The phase transition II-III is also of the order-disorder type. However, the entropy $\Delta S \approx 2.2 \mathrm{cal} \cdot \mathrm{mol}^{-1} \cdot \mathrm{deg}^{-1}$ of this transition is much larger than the configurational entropy associated only with proton ordering in the acid $\mathrm{H}$-bonds double-well potentials $\left(\Delta S \approx 1.3 \mathrm{cal} \cdot \mathrm{mol}^{-1} \cdot \mathrm{deg}^{-1}\right)$. Moreover, its temperature is not changed by deuteration. According to results of X-ray study ${ }^{[10]} \mathrm{C}$-centered lattice disappears in Phase III and the acid hydrogen bonds become asymmetric. Hence, the phase transition II-III can be triggered by orientational ordering of $\mathrm{NH}_{4}^{+}(1)$ ions and accompanied by partial ordering of acid protons in asymmetric hydrogen bonds.

A specific feature of low temperature phases of TAHS is a ferroelectric soft mode which exists in a wide temperature range including phases II $-\mathrm{V}$. 


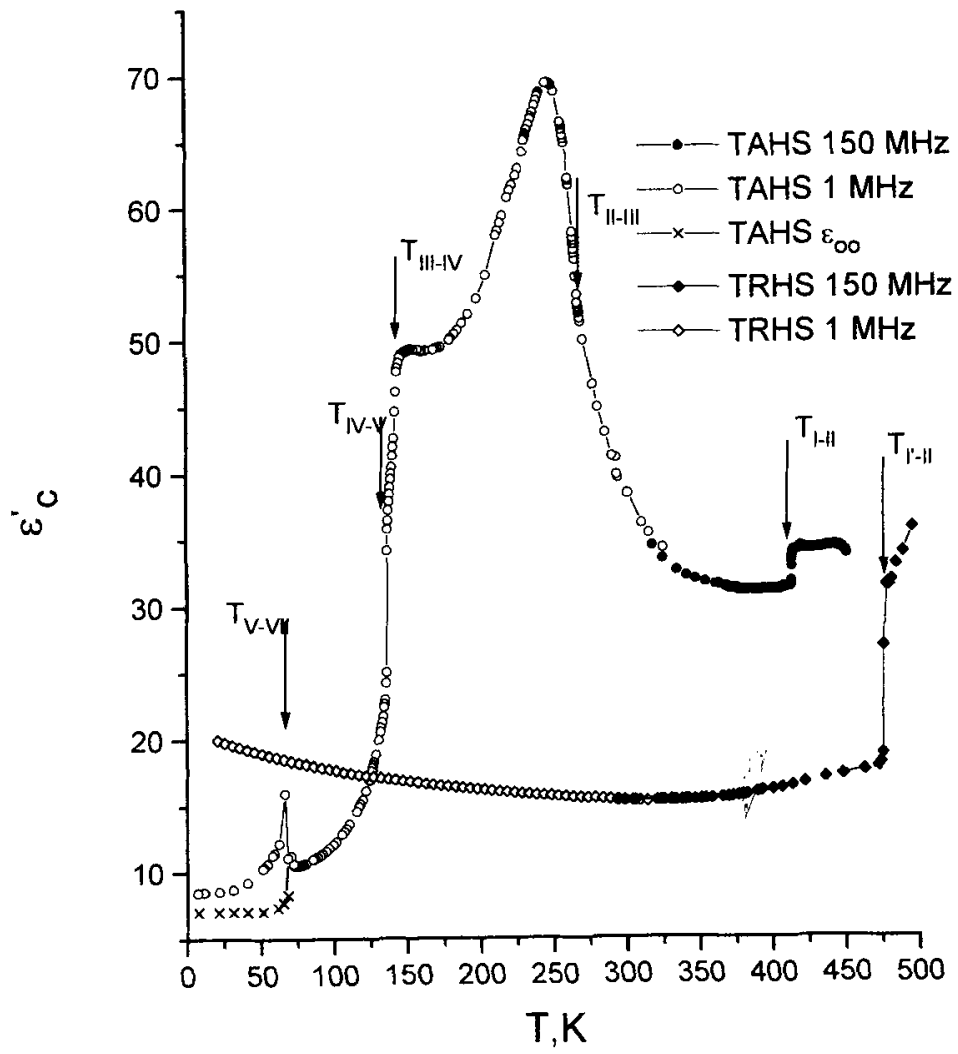

FIGURE 2 Temperature dependences of dielectric constant $\varepsilon_{c}$ in $\left(\mathrm{NH}_{4}\right)_{3} \mathrm{H}\left(\mathrm{SO}_{4}\right)_{2}$ and $\mathrm{Rb}_{3} \mathrm{H}\left(\mathrm{SO}_{4}\right)_{2}$.

The temperature dependence of the soft mode is reflected in the CurieWeiss behavior of the $\varepsilon_{c}(T)$ dependence over all these phases (Fig. 2). The values of Curie constants $C$ are about $10^{3} \mathrm{~K} \quad\left(C_{\mathrm{II}}=2.9 \cdot 10^{3} \mathrm{~K}\right.$, $C_{\mathrm{III}}=1.4 \cdot 10^{3} \mathrm{~K}, C_{\mathrm{IV}} \approx C_{\mathrm{V}} \approx 0.6 \cdot 10^{3} \mathrm{~K}$ ) and are typical for proper orderdisorder ferroelectric or antiferroelectric transitions. The smoothed maximum on dependence of $\varepsilon_{c}(T)$ does not correspond to any structural phase transition and could be assigned to a trace of over-critical phase transition. ${ }^{[18]}$ The phase transition III-IV is of second order, while IV-V is of first order. These transitions are accompanied by small entropy changes, which suggests small differences of degree of ammonium and acid proton ordering in phases III, IV and V. Hence the Curie-like behavior of $\varepsilon_{c}$ in Phases IV and V is indicative of antiferroelectric ordering below $T_{\text {III-IV, }}$ although double hysteresis loops were not observed in these phases. 


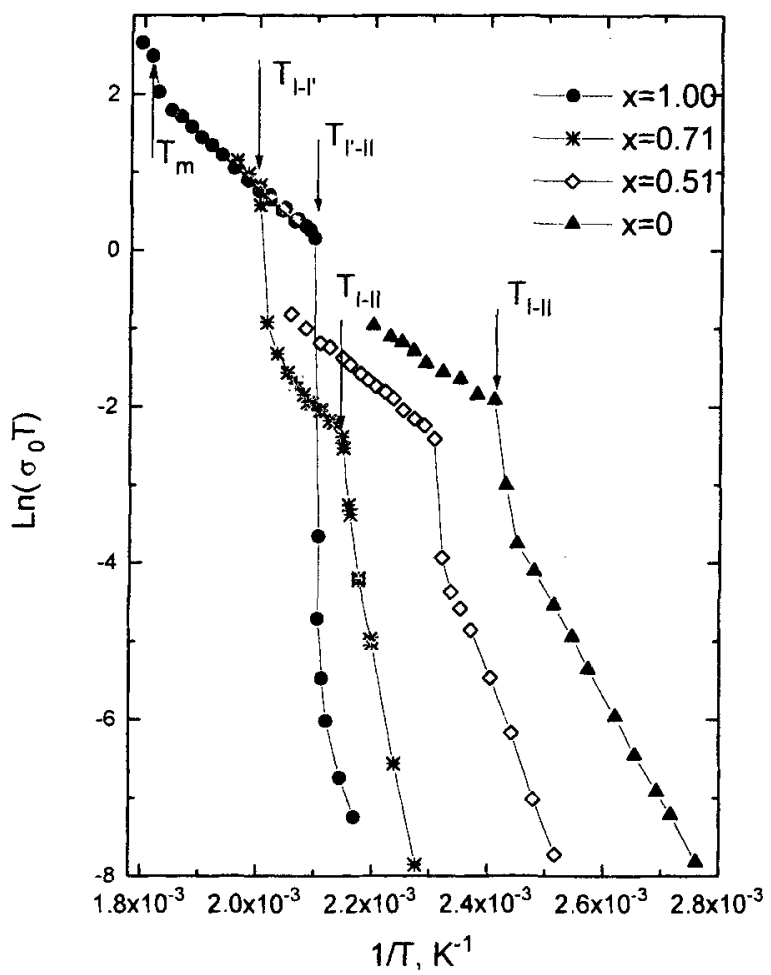

FIGURE 3 Arrhenius plot of bulk dc conductivity $\sigma_{0}$ in $\left[\left(\mathrm{NH}_{4}\right)_{1-x} \mathrm{Rb}{ }_{x}\right]_{3} \mathrm{H}\left(\mathrm{SO}_{4}\right)_{2}$ crystals measured along the $c$ axis.

Our results show a step-like increase of $\varepsilon_{c}$ at the first order phase transition V-VII which we attribute to domain dielectric dispersion in ferroelectric Phase VII (Fig. 2). The dielectric constant $\varepsilon_{\infty}$ of a single domain sample calculated from frequency dependencies of complex dielectric constant in frequency range $10 \mathrm{~Hz}-1 \mathrm{MHz}$ shows quite different behavior from that measured at $1 \mathrm{MHz}$. Thus, in the vicinity of the ferroelectric transition V-VII the dependence of $\varepsilon_{c}(T)$ does not obey the Curie-Weiss law either above nor below $T_{\mathrm{V}-\mathrm{VII}}$. Therefore this phase transition can be interpreted as a transition between two ordered phases: antiferroelectric and ferroelectric.

\section{2. $\mathrm{Rb}_{3} \mathrm{H}\left(\mathrm{SO}_{4}\right)_{2}$ Crystal}

According to results of previous studies, ${ }^{[8]}$ TRHS exhibits two irreversible structural phase transitions at 329 and $399 \mathrm{~K}$. Our experiments do not 
confirm the existence of these phase transitions. However, a well defined reversible first order phase transition was detected at temperature $T_{\mathrm{I}^{\prime}-\mathrm{II}}=476 \mathrm{~K}$ which is $50 \mathrm{~K}$ lower than the melting point. In the vicinity of this transition the anomaly of temperature dependence of protonic conductivity is quite similar to that observed at the superprotonic phase transition I-II in TAHS (Fig. 3). Therefore, we can conclude that hightemperature phase $I^{\prime}$ in TRHS is also superprotonic. Disappearing of anisotropy of dc conductivity and high-frequency dielectric constant in phase $\mathrm{I}^{\prime}$ is consistent with cubic symmetry, but a cubic phase for such a complex material seems unlikely and would have to be confirmed by X-ray diffraction. In TAHS, the superprotonic paraelastic phase I is trigonal.

Below $T_{\mathrm{I}^{\prime}-\mathrm{II}}, \varepsilon_{c}$ increases with decreasing temperature in accord with the Curie-Weiss law. The value of Curie constant $C=1.5 \cdot 10^{3} \mathrm{~K}$ is close to that obtained by Gesi in earlier dielectric experiments ${ }^{[6]}$ where also it was shown that no phase transition is observed in TRHS down to $4.2 \mathrm{~K}$.

\section{Mixed $\left[\left(\mathrm{NH}_{4}\right)_{1-x} \mathrm{Rb}_{x}\right]_{3} \mathrm{H}\left(\mathrm{SO}_{4}\right)_{2}$ Crystals}

At low $\mathrm{Rb}$ concentrations $(x \leq 0.05)$, strong smearing of the anomalies in dielectric constant and excess part of specific heat $\Delta C_{p}$ is observed in the vicinity of the phase transitions II-III, III-IV and IV-V (Fig. 4). Above and below $T_{\mathrm{I}-\mathrm{II}}$, the anomalous tails of $\Delta C_{p}(T)$ increase with increasing $\mathrm{Rb}$ content up to $x \approx 0.05$. However, at $x=0.09$ this anomaly is completely suppressed. Similar behavior is observed for $\Delta C_{p}(T)$ at phase transition III-IV.

An especially strong effect of $\mathrm{Rb}-\mathrm{NH}_{4}$ substitution is observed for phase transition IV-V. At $x \approx 0.03$ the step-like dielectric anomaly at this phase transition disappears and only a weak and broad anomaly is observed for $\Delta C_{c}(T)$ (Fig. 4).

The anomaly $\varepsilon_{c}(T)$ corresponding to ferroelectric phase transition V-VII is not observed for $x \geq 0.03$ down to experimental temperature limit $18 \mathrm{~K}$. This means that transition V-VII either is suppressed completely or shifted towards $T \rightarrow 0$. Representative results of concentration dependence of $\varepsilon_{c}(T)$ at low temperatures are shown in Figure 5. With increasing $x$ the step-like anomaly at the ferroelectric transition disappears and is replaced by glass-like anomaly at $x \geq 0.05$. The difference in the dielectric properties can be seen much clearer in the temperature dependence of dielectric loss $\varepsilon^{\prime \prime}$ (Fig. 5a).

Summarizing the results of calorimetric and dielectric measurements, we can conclude that for compounds with $1 \geq x \geq 0.05$, the monoclinic 

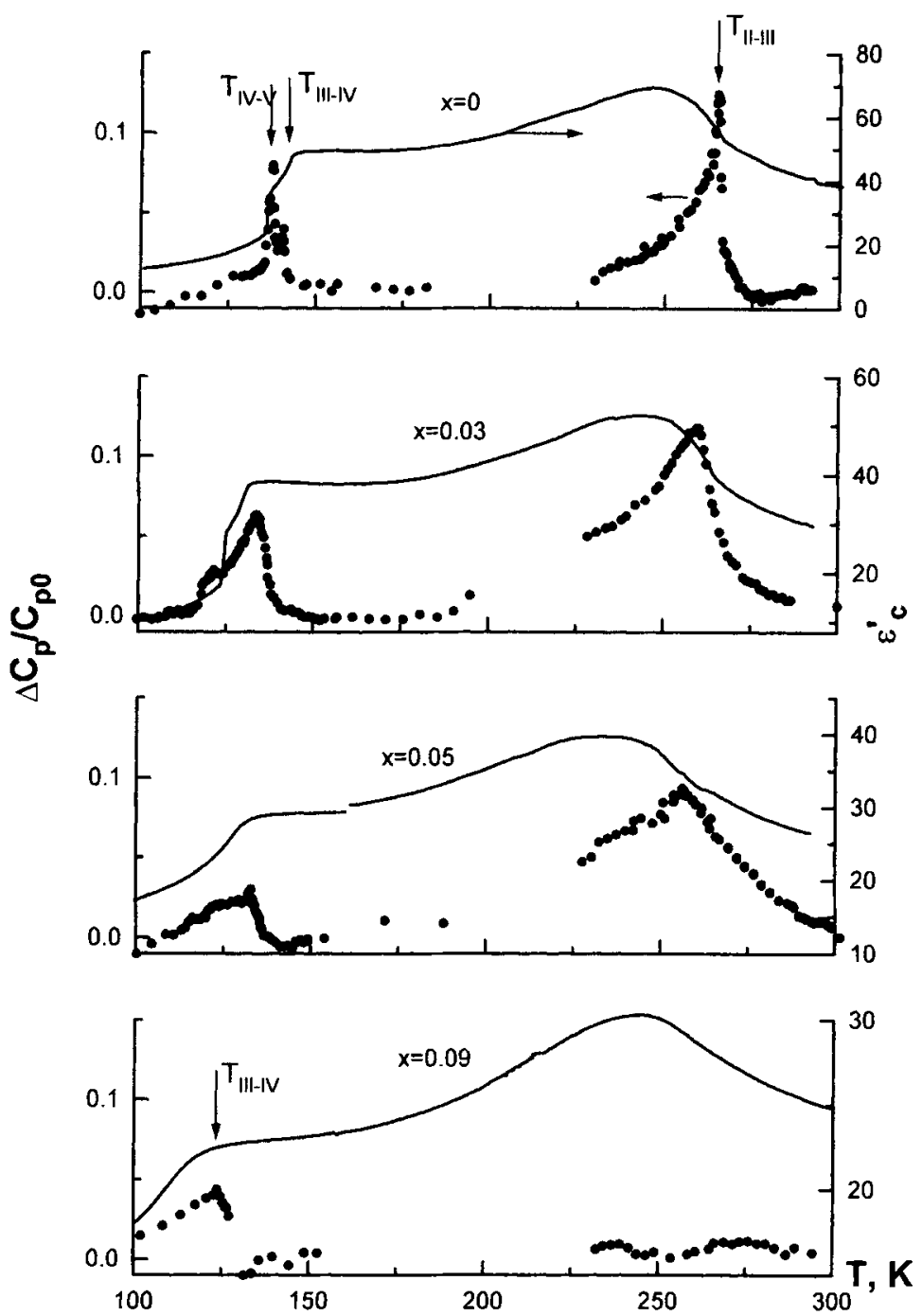

FIGURE 4 Temperature dependences of dielectric constant $\varepsilon_{c}$ measured at $1 \mathrm{MHz}$ (solid line) and excess part of specific heat $\Delta C_{p}$ (open circles) in $\left[\left(\mathrm{NH}_{4}\right)_{1-x} \mathrm{Rb}_{x}\right]_{3} \mathrm{H}\left(\mathrm{SO}_{4}\right)_{2}$ crystals.

symmetry $(A 2 / a)$ persists from the superprotonic phase transitions down to $0 \mathrm{~K}$ (Fig. 6). The concentrations $x \approx 0.05$ and $x \approx 0.9$ correspond to the critical upper and lower concentrations for the glass regime which exists at low temperatures. 

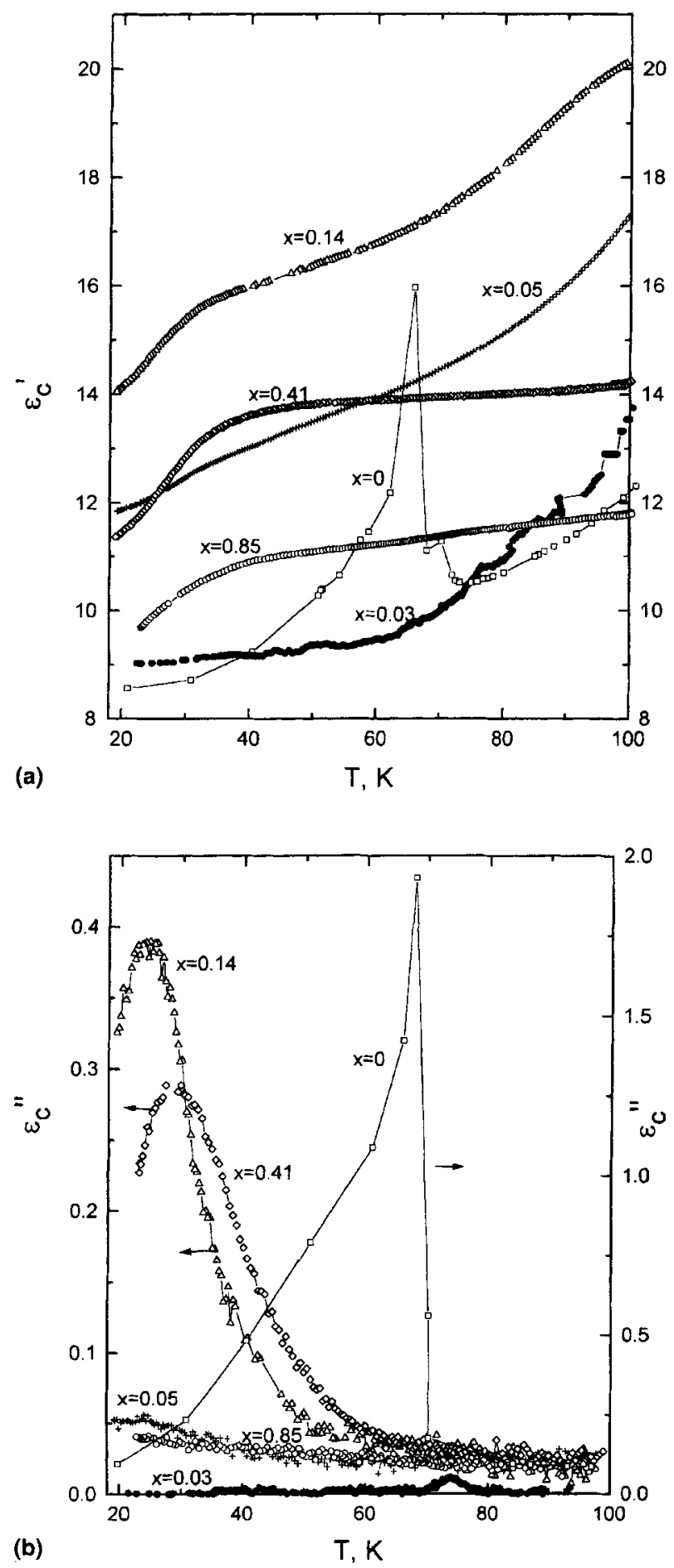

FIGURE 5 Temperature dependences of real (a) and imaginary (b) part of complex dielectric constant $\varepsilon_{c}^{*}$ measured at $1 \mathrm{MHz}$ in $\left[\left(\mathrm{NH}_{4}\right)_{l-x} \mathrm{Rb}_{x}\right]_{3} \mathrm{H}\left(\mathrm{SO}_{4}\right)_{2}$ crystals. 


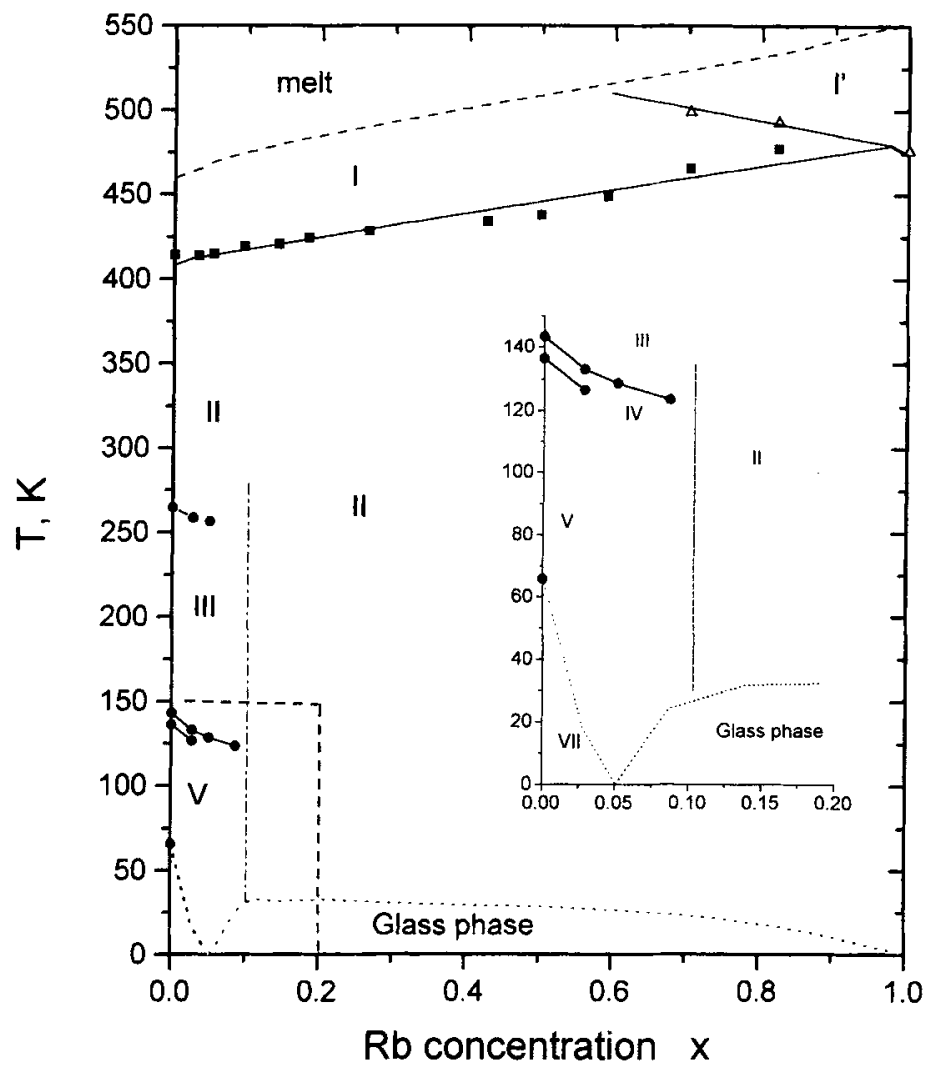

FIGURE $6 x, T$ phase diagram of $\left[\left(\mathrm{NH}_{4}\right)_{1-x} \mathrm{Rb}_{x}\right]_{3} \mathrm{H}\left(\mathrm{SO}_{4}\right)_{2}$ determined from dielectric, conductivity and calorimetric data.

\section{CONCLUSION}

Dielectric and calorimetric measurements of our newly investigated mixed $\left[\left(\mathrm{NH}_{4}\right)_{1-x} \mathrm{Rb}_{x}\right]_{3} \mathrm{H}\left(\mathrm{SO}_{4}\right)_{2}(0 \leq x \leq 1)$ crystals have been performed in the temperature range $18-600 \mathrm{~K}$. A new high-temperature superprotonic phase was detected for compositions with $x>0.6$. It was found that even small rubidium concentrations $(x \approx 0.03)$ strongly suppress the low-temperature structural phase transitions II-III $(T=265 \mathrm{~K})$, III - IV $(141 \mathrm{~K})$, IV -V $(133 \mathrm{~K})$ and shift down to liquid helium temperature the ferroelectric phase transition V-VII. A proton glass state region was discovered below $35 \mathrm{~K}$ for compositions with $0.05 \leq x \leq 0.9$. 


\section{Acknowledgements}

Dr. S. C. Meschia is gratefully acknowledged for assistance with the dielectric measurements. Financial support from NSF Grant DMR-9520251 and RFBI Grant N96-02-17754 is also gratefully acknowledged S. L.-M. thanks the Basque Government for support under grant BFI96.041.

\section{References}

[1] Jona, F. and Shirane, G. (1962). Ferroelectric Crystals, Pergamon Press, Oxford.

[2] Ohi, K., Osaka, J. and Uno, H. (1978). J. Phys. Soc. Jpn., 44, 529.

[3] Paash, M., Winterlich, M., Bohmer, R., McIntyre, G. J. and Loidl, A. (1996). Z. Phys., B99, 333.

[4] Gesi, K. (1977). J. Phys. Soc. Jpn., 42, 1785.

[5] Osaka, T., Makita, J. and Gesi, K. (1980). J. Phys. Soc. Jpn., 49, 599.

[6] Gesi, K. (1980). J. Phys, Soc. Jpn., 48, 886.

[7] Gesi, K. (1980). Jpn. J. Appl. Phys., 19, 1051.

[8] Ichikawa, M. (1980). J. Phys. Soc. Jpn., 45, 355.

[9] Suzuki, S. and Makita, Y. (1978). Acta Cryst., B34, 732.

[10] Kamoun, M., Ben Ghozlen, M. H. and Daoud, A. (1987). Phase Tans., 9, 247.

[11] Fortier, S., Frazer, M. E. and Hyding, D. (1985). Acta Cryst., C41, 1139.

[12] Osaka, T., Makita, Y. and Gesi, K. (1980). J. Phys. Soc. Jpn., 49, 593.

[13] Gesi, K. and Ozawa, K. (1977). J. Phys. Soc. Jpn., 43, 570.

[14] Baranov, A. I. and Waplak, S. (1998). JETP Lett., in press.

[15] Schwalovaky, L., Vinnichenko, V. Yu., Baranov, A. I., Bismayer, U., Merinov, B. V. and Escold, G. (1988). J. Phys. C., in press.

[16] Suzuki, S., Oshino, Y., Gesi, K. and Makita, Y. (1979). J. Phys. Soc. Jpn., 47, 874.

[17] Baranov, A. 1., Merinov, B. V., Tregubchenko, A. V., Khiznichenko, V. P., Shuvalov, L. A. and Schagina, N. M. (1989). Solid State Ionics, 36, 289.

[18] Gesi, K. (1977). J. Phys. Soc. Jpn., 43, 1941. 